\title{
Food Deprivation: A Neuroscientific Perspective
}

\author{
Harald T. Schupp and Britta Renner
}

$\begin{array}{ll}\text { Abbreviations } \\ \text { AgRP } & \text { Agouti-related protein } \\ \text { BOLD } & \text { Blood oxygenation level dependent } \\ \text { EEG } & \text { Electroencephalography } \\ \text { ERP } & \text { Event related potential } \\ \text { fMRI } & \text { Functional magnetic resonance imaging } \\ \text { LiCL } & \text { Lithium chloride } \\ \text { LPP } & \text { Late positive potential } \\ \text { MNE } & \text { Minimum norm estimate } \\ \text { Nc } & \text { Nucleus } \\ \text { NPY } & \text { Neuropeptide Y } \\ \text { PET } & \text { Positron emission tomography } \\ \text { POMC } & \text { Proopiomelanocortin } \\ \text { rCBF } & \text { Regional cerebral blood flow } \\ \text { ROI } & \text { Region of interest }\end{array}$

\subsection{Introduction}

The Russian physiologist Pavlov considered eating as the most powerful relationship an organism has to its surrounding world (Pavlov 1953). This "food connection" is heavily regulated by internal state variables such as hunger. Prolonged periods of starving are one of the most tragic experiences of humanity and even mild conditions of food deprivation clearly affect consummatory behavior as reflected in the saying "hunger is the best spice".

Everybody knows about the effects of deprivation. The effects appear intuitively so obvious that the phenomenon receives paradoxically rather too little than too much attention. Consider for instance the work of Pavlov and Skinner, in which food stimuli play a central role. The empirical finding that the contingent pairing of a tone and food establishes new behaviors is nowadays taught in high school. After training, the dog salivates to a previously neutral stimulus. Similarly, knowledge

H.T. Schupp (困)

Department of Psychology, University of Konstanz, 78457 Konstanz, Germany

e-mail:harald.schupp@uni-konstanz.de 
about the Skinner box, in which rats may learn to vigorously press a button to obtain food, is well perceived in the public. Imagine what would happen, if the animals were tested while satiated? The simple answer is they would probably not learn to press the button or to salivate. The role of deprivation in these learning principles is easily overlooked. However, Pavlov was very clear in his writing by stating that even the most avaricious dog will not learn the salivary response when satiated (Pavlov 1953). Accordingly, internal state variables have profound effects on responding to and learning about food cues.

In humans, the effects of prolonged periods of reduced food consumption were investigated in the Minnesota semi-starvation experiment, which was conducted during Second World War by Keys and colleagues (Keys et al. 1950). Food intake was greatly limited for several months resulting in pronounced loss of body weight $(\sim 25 \mathrm{~kg})$. The experiment revealed massive physiological and psychological effects of semi-starvation. One notable finding is that food became the most important thing in life (Keys et al. 1950). Preoccupation with food and episodes of binge eating may be also induced by voluntary restricting food intake as in dieting and restrained eating (Polivy 1996). However, deprivation need not be sustained over long periods to affect the human feeding system. Acute food deprivation is associated with increased food consumption compared to nondeprived control groups (Spiegel et al. 1989; Drobes et al. 2001; Mauler et al. 2006) and increases the reinforce value of food in behavioral choice paradigms (Raynor and Epstein 2003).

\subsection{Deprivation and the Feeding System: Conceptual Considerations}

Deprivation affects almost every aspect related to food intake. Animal research over the past decade allows sketching a basic scheme of the feeding system providing a conceptual framework for the understanding of the effects of food deprivation on ingestive behaviors. As illustrated in Fig. 142.1, the organization of goal-directed ingestive behaviors rests on the integration of information about internal state (e.g., food deprivation), cues from the environment (e.g., availability of palatable food), and behavioral state (e.g., circadian rhythm). Furthermore, ingestive behavior is temporally organized in distinct appetitive and consummatory phases (cf., Timberlake 2001). To obtain food, one has first to look for potential food sources. A general search mode occurs when the subject does not know where to look for food. Exploratory behaviors bring the organism close to food and a focal search mode is engaged readying the organism for consummatory behaviors of chewing and swallowing. Ethological observations reveal reflexive-stercotypic bchaviors during food consumption, while appetitive behaviors are more variable and non-stereotypic. These motivational stages differ in many respects such as temporal and spatial proximity to food consumption, engagement of distinct perception-action units, and specific cues sensitizing the engagement of stages. Recent research also suggests that the weighting of external and internal information differs among motivational stages. When food was readily available, consumption was controlled by the palatability of the food independent whether the animal underwent food restriction ( $85 \%$ of normal weight) or not. Conversely, measurement of anticipatory locomotor behaviors revealed significant deprivation effects, which were independent from food palatability (Barbano and Cador 2005).

Great progress has been made to delineate mechanisms how information about internal state is represented in the brain and controls ingestive behaviors. The brain perceives an array of interosensory signals conveying information about the availability of food and nutrients generated by the gastrointestinal tract, postabsorptive sites (pancreas, liver, muscle), and stored nutrients in adipose tissue (Woods et al. 2000; Berthoud and Morrison 2008). While it is recognized that multiple brain regions are important for perceiving internal state, specific nuclei in the hypothalamus are consid- 


\section{Basic Scheme of the Feeding System}

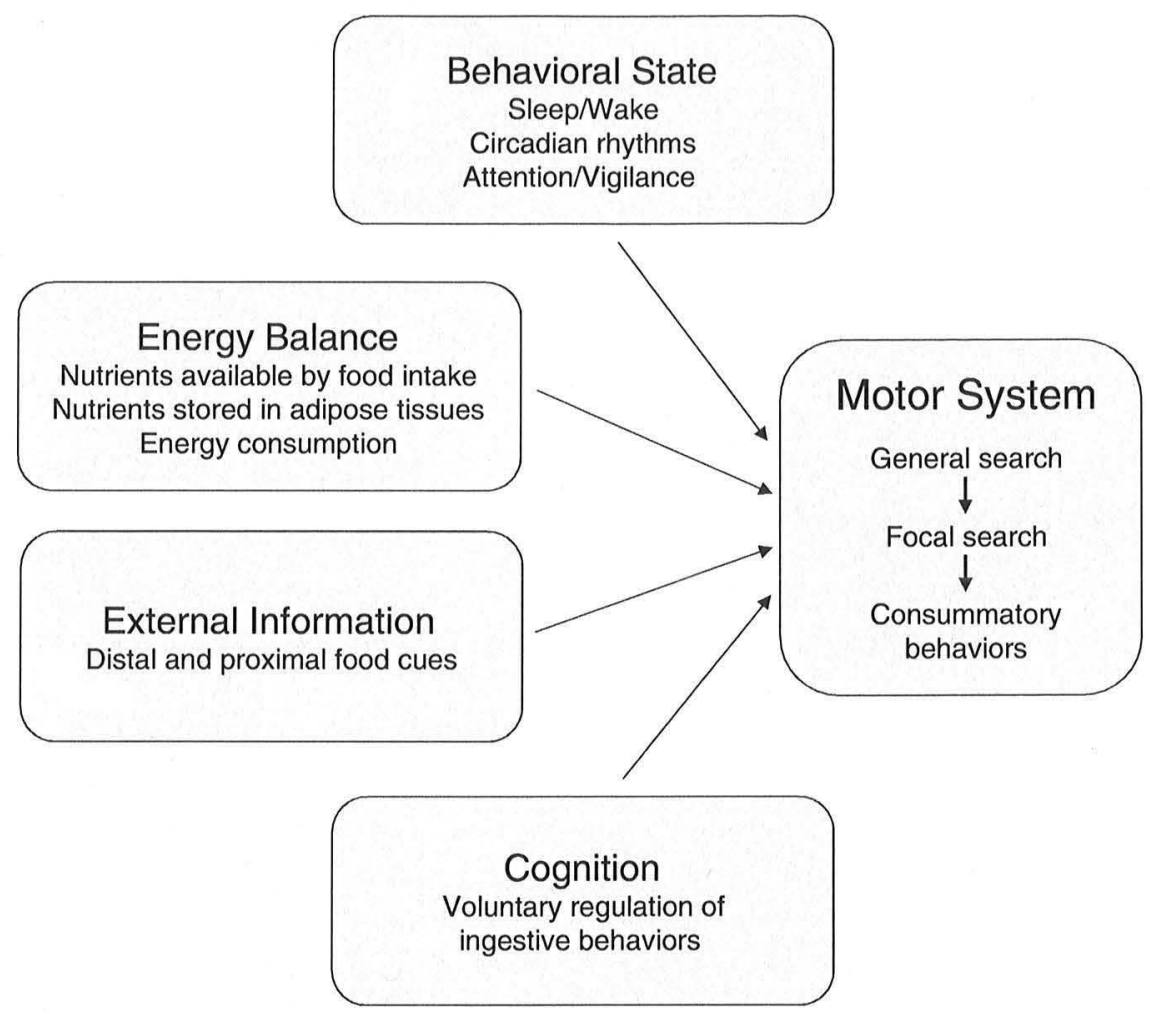

Fig. 142.1 Conceptual framework of the organization of the feeding system (Based on Swanson 2000; Timberlake 2001)

ered as key sites for the integration of metabolic-related information. The nucleus (Nc) arcuatus is assumed to integrate metabolic information via two populations of neurons (Neuropeptide Y (NPY)/ Agouti-related Protein (AgRP), Proopiomelanocortin (POMC)). These neurons are sensitive to a number of metabolic-related information (e.g., leptin, insulin, ghrelin) and exert opposite actions on feeding behavior. Efferents from these neurons to the paraventricular, lateral, and ventromedial hypothalamus provide a gateway for the translation of metabolic information to adaptive feeding responses as these neurons project widely through the entire brain (Swanson 2000; Watts and Swanson 2002; Berthoud and Morrison 2008). Based on anatomical, developmental, genetic, and functional data, Swanson introduced the concept of the behavioral control column in the rostral hypothalamus, which is considered as key motor control structure for motivated behaviors of feeding, reproduction, and defense (Swanson 2000). Consistent with its presumed role for ingestive behaviors, the paraventricular Nc affects many brain regions implicated in the selection, planning, and execution of specific somatic motor behaviors (cortical, striatal, and pallidal motor structures, brain stem motor nuclei), endocrine and autonomic responses and behavioral state regulation (see Fig. 142.2a). Overall, distinct nuclei in the rostral hypothalamus appear critical for the representation of internal state and provide mechanisms how food deprivation exerts motivational control on ingestive behaviors.

The incentive value of food is dynamically adjusted according to variations in internal state of energy balance. Even the tastiest food item is not consumed when satiated. This finding requires that 


\section{Neural Mechanisms of the Feeding System}

a

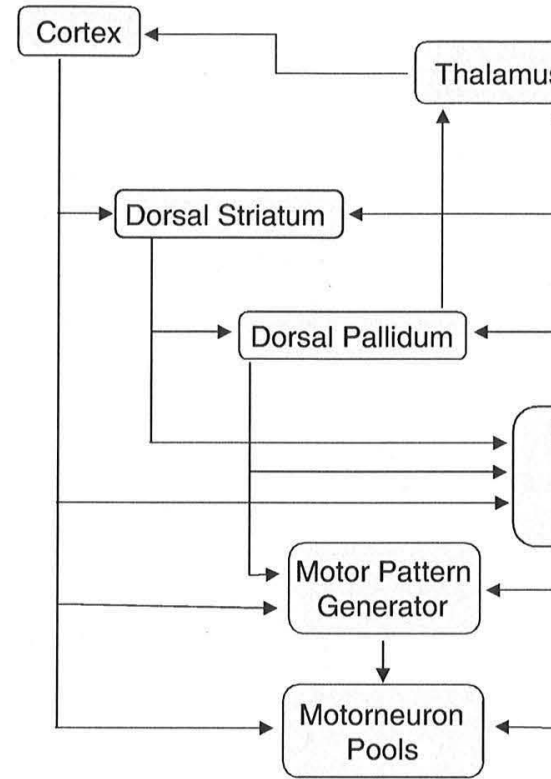

Motivated Behaviors

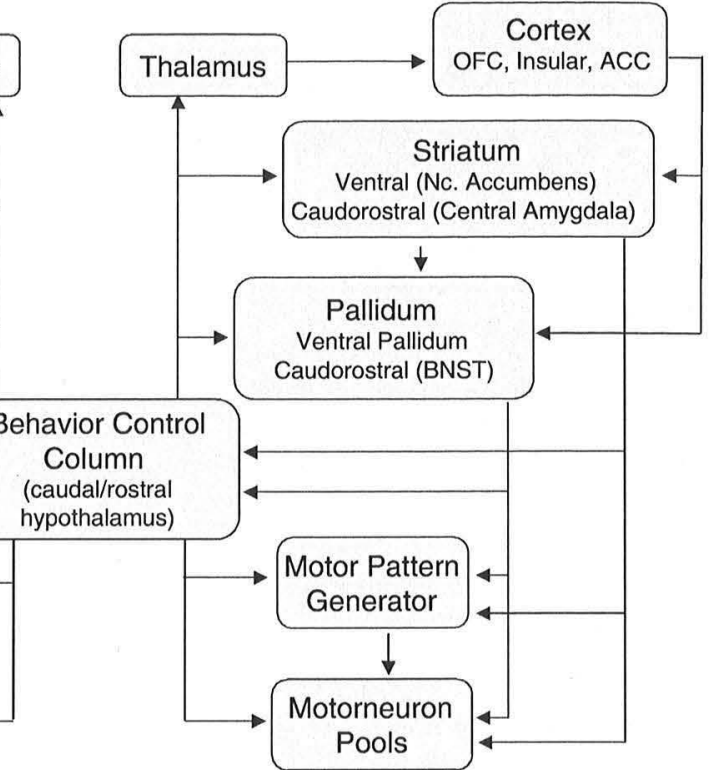

b

Key Structures of the Motive Circuitry

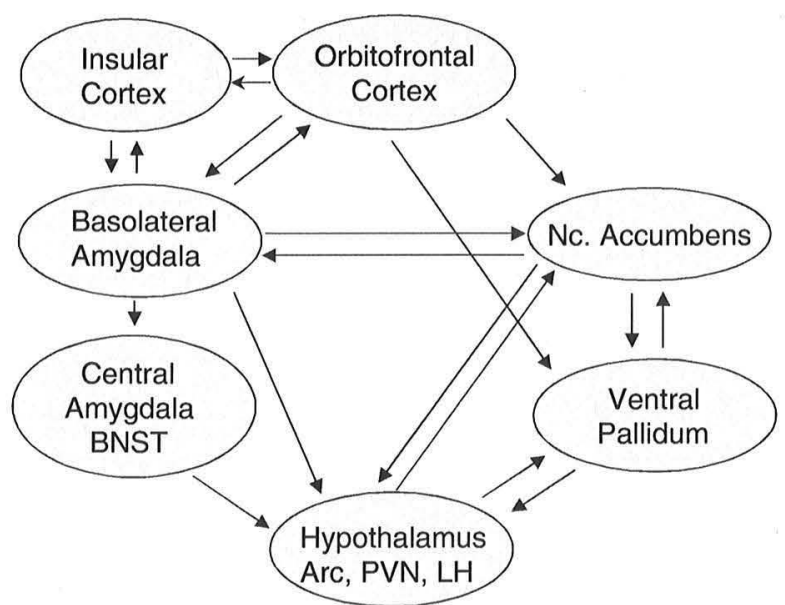

Fig. 142.2 (a) Illustration of the concept of the behavioral control column in the medial zone of the hypothalamus. The rostral segment is thought to regulate basic classes of motivated behaviors (ingestive, reproductive, defensive). Exploratory or foraging behaviors are assumed to involve the caudal segment (The graph is based on Swanson (2000) and Watts \& Swanson (2002) and the reader is directed to these sources for details) (b) Schematic diagram of key structures of the motive circuitry implicated in the perception of reward and the activation of adaptive behavioral responses

reward perception is at least in some neural structures profoundly dependent on internal state of energy balance. Many neural structures sensitive to food reward have been revealed in the past decade. In the rat, a motive circuitry has been delineated responding to appetitive food stimuli including regions in the orbitofrontal cortex, insular cortex, amygdala, Nc. Accumbens, ventral pallidum, 
ventral tegmental area, and dorsal thalamus (see Fig. 142.2b; Kalivas and Nakamura 1999; Holland and Gallagher 2004; Berridge and Kringelbach 2008; Smith et al. 2009). While the specific contributions of these structures to the organization of motivated behaviors remains to be determined, unique contributions among selected structures in controlling ingestive behaviors have been demonstrated. For instance, recent research has revealed "hedonic hot spots" in the Nc. accumbens and ventral pallidum of the rat brain with different functions in instrumental responding to and consumption of food and hedonic liking responses measured by facial expression (Smith et al. 2009). Furthermore, core structures of the motive circuitry are differentially implicated in the phenomenon of classically conditioned eating. In the learning phase, a cue is repeatedly presented when hungry rats are allowed to eat. During testing, presentation of this cue can stimulate eating even when the rat is satiated. A recent study suggests that this phenomenon relies on direct pathways from orbitofrontal cortex and basolateral nuclei of the amygdala but not from Nc. accumbens (Petrovich et al. 2005). Furthermore, new learning induced by devaluation of the food with LiCL (lithium chloride) is abolished when the orbitofrontal cortex but not the amygdala is lesioned before the devaluation procedure (Pickens et al. 2003). Thus, the orbitofrontal cortex seems to be critical for learning about changes in the stimulusreinforcement contingencies. Further differentiation among the contribution of neural structures of the motive circuitry is suggested when considering the inhibition of the feeding response by fear. Specifically, inhibition of feeding by presenting a classically conditioned fear stimulus is abolished when leasoning the central (but not the basolateral) nuclei of the amygdala (Petrovich et al. 2009). Overall, an interconnected network of neural structures has been revealed which mediates reward perception and provides gateways to the engagement of feeding motivation and the organization of appropriate motor responses. In humans, a growing number of studies investigated the hypothesis that core structures of reward perception are sensitive to incentive value using functional neuroimaging (e.g., Arana et al. 2003; Killgore et al. 2003; Kringelbach et al. 2003; Beaver et al. 2006; Porubská et al. 2006; Schienle et al. 2009). Despite notable differences, the findings support the notion that incentive value modulates neural activity in core structures of reward processing.

\subsection{Food Deprivation and Incentive Value}

The understanding of the neural organization of reward perception provides a roadmap for the neuroscientific examination of deprivation effects in humans. Early studies investigating fasting and satiation effects on brain activity revealed that neural activity decreased among other regions in several structures of the motive circuitry including orbitofrontal cortex, insular cortex, basal ganglia, and hypothalamus in satiated as compared to hungry state (Tataranni et al. 1999; Delparigi et al. 2002 , 2005). These findings imply that hunger may have profound effects on resting state activity of the motive circuitry in the absence of external stimulation.

More recent studies investigated the effects of food deprivation on food-related stimulus processing. Incentive motivation theory posits that incentive value of food items is modulated by physiological drive states (Toates 1981). According to this hypothesis, core structures of the motive circuitry are expected to show increased activity to food-related stimuli in deprived as compared to satiated state. To identify relevant studies, a literature research on public databases (PubMed, Web of Science) was conducted using a variety of key words (e.g., hunger, deprivation, eating, food). Nine studies were identified, which directly contrasted deprived and satiated state and measured brain activity in the motive circuitry to the presentation of food-related stimuli (Tables 142.1 and 142.2).

Hemodynamic measures were used in all studies with functional magnetic resonance imaging (fMRI) being more common than positron emission tomography (PET), in particular in most recent 
Table 142.1 Schematic overview of fMRI- and PET-studies investigating deprivation effects on food stimulus processing

\begin{tabular}{|c|c|c|c|c|c|c|c|c|}
\hline & $\mathrm{N}$ & $\begin{array}{l}\text { Hours of } \\
\text { deprivation (h) }\end{array}$ & $\begin{array}{l}\text { Day time } \\
\text { of session }\end{array}$ & $\begin{array}{l}\text { Manipulation } \\
\text { check }\end{array}$ & $\begin{array}{l}\text { Assessment } \\
\text { of eating }\end{array}$ & Method & Task & Stimuli \\
\hline $\begin{array}{l}\text { LaBar et al. } \\
\qquad(2001)\end{array}$ & $\begin{array}{l}9 \\
\text { (8 women) }\end{array}$ & $\sim 8$ & $5: 00-8: 00 \mathrm{pm}$ & Self-report & & $\begin{array}{l}1.5 \mathrm{~T} \text { fMRI } \\
\text { Event-related } \\
\text { Design }\end{array}$ & Control task & $\begin{array}{l}\text { Pictures of foods and } \\
\text { objects }\end{array}$ \\
\hline $\begin{array}{l}\text { Uher et al. } \\
\text { (2006) }\end{array}$ & $\begin{array}{l}18 \\
\text { (10 women) }\end{array}$ & $\sim 24$ & $12: 30-1: 30 \mathrm{pm}$ & $\begin{array}{l}\text { Self-report } \\
\text { Biochemical } \\
\text { measures }\end{array}$ & $\begin{array}{c}\text { Three Factor Eating } \\
\text { Questionnaire }\end{array}$ & $\begin{array}{l}1.5 \mathrm{~T} \text { fMRI } \\
\text { Event-related \& } \\
\text { Block-Design }\end{array}$ & $\begin{array}{l}\text { Evaluative } \\
\text { rating task }\end{array}$ & $\begin{array}{l}\text { Pictures of Foods and } \\
\text { Objects } \\
\text { Taste of chicken broth, } \\
\text { chocolate milk, } \\
\text { saliva }\end{array}$ \\
\hline $\begin{array}{l}\text { Goldstone et al. } \\
\text { (2009) }\end{array}$ & $\begin{array}{l}20 \\
\text { (10 women) }\end{array}$ & $\sim 16$ & $11: 00-12: 00 \mathrm{am}$ & Self-report & $\begin{array}{l}\text { Dutch Eating Behavior } \\
\text { Questionnaire } \\
\text { SCOFF }\end{array}$ & $\begin{array}{l}3 \mathrm{~T} \text { fMRI } \\
\text { Block-Design }\end{array}$ & $\begin{array}{l}\text { Evaluative } \\
\text { rating task }\end{array}$ & $\begin{array}{l}\text { Pictures of low- and } \\
\text { high-caloric foods } \\
\text { and objects }\end{array}$ \\
\hline $\begin{array}{l}\text { Hinton et al. } \\
\text { (2004) }\end{array}$ & $\begin{array}{l}12 \\
\text { (0 women) }\end{array}$ & $\sim 18$ & $12: 30-1: 30 \mathrm{pm}$ & $\begin{array}{l}\text { Self-report } \\
\text { Biochemical } \\
\text { measures }\end{array}$ & & $\begin{array}{l}\text { PET } \\
\text { Block-Design }\end{array}$ & $\begin{array}{l}\text { Evaluative } \\
\text { rating task }\end{array}$ & $\begin{array}{l}\text { Low and high } \\
\text { incentive menus }\end{array}$ \\
\hline $\begin{array}{l}\text { Piech et al. } \\
\text { (2009) }\end{array}$ & $\begin{array}{l}8 \\
\text { (3 women) }\end{array}$ & $\sim 6$ & $6: 00-7: 00 \mathrm{pm}$ & Self-report & $\begin{array}{l}\text { History of eating } \\
\text { disorder }\end{array}$ & $\begin{array}{l}1.5 \mathrm{~T} \text { fMRI } \\
\text { Event-related } \\
\text { Design }\end{array}$ & $\begin{array}{l}\text { Evaluative } \\
\quad \text { rating task }\end{array}$ & $\begin{array}{l}\text { Low and high } \\
\text { incentive menus }\end{array}$ \\
\hline $\begin{array}{l}\text { Morris and } \\
\text { Dolan } \\
(2001)\end{array}$ & $\begin{array}{l}10 \\
\text { (1 woman) }\end{array}$ & $\sim 16$ & $4: 00-5: 00 \mathrm{pm}$ & $\begin{array}{l}\text { Self-report } \\
\quad \text { Biochemical } \\
\text { measures }\end{array}$ & $\begin{array}{l}\text { History of eating } \\
\text { disorder }\end{array}$ & $\begin{array}{l}\text { PET Block- } \\
\text { Design }\end{array}$ & $\begin{array}{l}\text { Picture } \\
\text { recognition } \\
\text { task }\end{array}$ & $\begin{array}{l}\text { Pictures of foods } \\
\text { and objects }\end{array}$ \\
\hline $\begin{array}{l}\text { Mohanty et al. } \\
\text { (2008) }\end{array}$ & 7 & $\sim 8$ & $?$ & Self-report & Restrained Eating & $\begin{array}{l}3 \mathrm{~T} \text { fMRI Mixed } \\
\text { Event-related } \\
\text { Design }\end{array}$ & $\begin{array}{l}\text { Spatial attention } \\
\text { task }\end{array}$ & $\begin{array}{l}\text { Food and object } \\
\text { pictures }\end{array}$ \\
\hline $\begin{array}{l}\text { Siep et al. } \\
\text { (2009) }\end{array}$ & $\begin{array}{l}12 \\
\text { (12 women) }\end{array}$ & $\sim 18$ & $1: 00-3: 00 \mathrm{pm}$ & Self-report & $\begin{array}{l}\text { History of eating } \\
\quad \text { disorder; } \\
\text { Restrained Eating }\end{array}$ & $\begin{array}{l}3 \mathrm{~T} \text { fMRI } \\
\text { Block-Design }\end{array}$ & $\begin{array}{l}\text { Attention task: } \\
\text { Attend taste, } \\
\text { Attend objects, } \\
\text { Attend bars }\end{array}$ & $\begin{array}{l}\text { Pictures of low- and } \\
\text { high caloric foods } \\
\text { and objects }\end{array}$ \\
\hline $\begin{array}{l}\text { Haase et al. } \\
\qquad(2009)\end{array}$ & $\begin{array}{l}18 \\
\text { (9 women) }\end{array}$ & $\sim 12$ & $11: 00-12: 00 \mathrm{am}$ & Self-report & $\begin{array}{c}\text { Three Factor Eating } \\
\text { Questionnaire }\end{array}$ & $\begin{array}{l}3 \mathrm{~T} \text { fMRI } \\
\text { Event-related } \\
\text { Design }\end{array}$ & No task & $\begin{array}{l}\text { Taste stimuli: caffeine, } \\
\text { saccharin, sucrose, } \\
\text { sodium chloride, } \\
\text { guanosin } 5 \\
\text { monophosphate }\end{array}$ \\
\hline
\end{tabular}

Summary of selected methodological aspects of fMRI- and PET-studies examining food deprivation 
Table 142.2 Key findings of deprivation effects

\begin{tabular}{|c|c|c|c|c|c|c|c|}
\hline Study & Effect & Orbitofrontal cortex & Insular cortex & Amygdala & Striatum & Hypothalamus & Other regions \\
\hline LaBar et al. (2001) & DEP & & & $\mathrm{L}$ & & & Fusiform R, Parahipp R \\
\hline Uher et al. (2006) & Vision: DEP & & & & & & Fusiform LR \\
\hline \multirow[t]{2}{*}{ Goldstone et al. (2009) } & DEP x CAL & LR & LR & LR & LR, ventral & & Hipp, ACC, DLPFC \\
\hline & $\begin{array}{l}\text { DEP: High vs. low CAL } \\
\text { SAT: High vs. low CAL }\end{array}$ & LR & LR & LR & LR, ventral & & \\
\hline \multirow[t]{3}{*}{ Hinton et al. (2004) } & DEP & & $\mathrm{L}$ & $\mathrm{R}$ & LR & $\mathrm{L}$ & Thal L, Brainstem, ACC R \\
\hline & Incentive & $\mathrm{L}$ & & $\mathrm{L}$ & & & \\
\hline & DEP $x$ Incentive & $\mathrm{L}$ & & & & & \\
\hline \multirow[t]{2}{*}{ Piech et al. (2009) } & Incentive & L, medial & & L & & & Cerebellum R \\
\hline & DEP x Incentive & $\mathrm{L}$, lateral & & & & & \\
\hline Morris and Dolan (2001) & Hunger & & $\mathrm{R}$, anterior & $\mathrm{R}$, anterior & $\mathrm{R}, \mathrm{NAcc}$ & $\mathrm{R}$ & \\
\hline Mohanty et al. (2008) & DEP $\times$ Picture & & & $\mathrm{R}$ & & & $\begin{array}{l}\text { Parahipp R, PCC LR, Brainstem } \\
\text { PC R, Peristriate cortex L }\end{array}$ \\
\hline Siep et al. (2009) & DEP $x$ Picture & $\begin{array}{l}\text { LR, medial } \\
\mathrm{L} \text {, lateral }\end{array}$ & $\mathrm{R}$ & & $\mathrm{L}$ & & Fusiform, PCC \\
\hline Uher et al. (2006) & Taste: DEP & & $\mathrm{L}$, anterior & & & & DLPFC R, MPFC R, Postcen L \\
\hline \multirow[t]{3}{*}{ Haase et al. (2009) } & $\begin{array}{l}\text { DEP: Sucrose } \\
\text { DEP: Saccharin }\end{array}$ & $\mathrm{R}$ & $\mathrm{R}$ & $\mathrm{R}$ & $\mathrm{R}$ & & $\begin{array}{l}\text { Parahipp LR, Thal R, Hipp LR } \\
\text { Parahipp R, Thal R, Hipp R }\end{array}$ \\
\hline & DEP: Caffeine & & & & $\mathrm{L}$ & LR & Parahipp LR, Thal LR, Hipp R \\
\hline & DEP: Citric acid & $\mathrm{R}$ & LR & LR & LR & $\mathrm{R}$ & Parahipp LR, Thal L, Hipp LR \\
\hline
\end{tabular}

$D E P$ deprivation, $C A L$ calorie, $S A T$ satiated, $L$ left, $R$ right, $A C C$ anterior cingulate cortex, $D L P F C$ dorsolateral prefrontal cortex, Fusiform fusiform gyrus, Hipp hippocampus, $M P F C$ medial prefrontal cortex, NAcc nucleus accumbens, $P C$ parietal cortex, $P C C$ posterior cingulate cortex, Parahipp parahippocampal cortex, Postcen postcentral gyrus, Thal thalamus 
studies. Accordingly, before considering empirical findings, basic principles of fMRI are briefly summarized. The technique is not measuring neural activity directly but associated epiphenomena, the local vascular response. Neuronal activation is associated with an increase in blood flow (cf., Logothetis 2008). For poorly understood reasons, the delivery of oxygenated hemoglobin is larger than local oxygen consumption. Oxygenated and deoxygenated hemoglobin have different magnetic properties and changes in their relative concentration can be revealed by magnetic resonance signals. Like other brain imaging methods assessing blood flow, temporal resolution is on the order of seconds as the changes in blood flow are relatively slow. However, spatial resolution is high as the brain is divided in small cubes (e.g., $1 \times 1 \times 1 \mathrm{~mm}$ ). The subtraction method is used to disclose deprivation effects on food cue processing in which the Blood Oxygenation Level Dependent (BOLD) signal to food cues under deprived versus satiated state is contrasted.

Three studies examined the processing of food and control pictures in deprived and satiated state. The first of these studies observed increased BOLD activity in the amygdala when viewing food pictures in a deprived state (LaBar et al. 2001). In contrast, Uher and colleagues (2006) observed no differential activity in the motive circuitry elicited by food pictures as a function of deprivation. A recent study revealed that deprivation effects in the motive circuitry may appear specifically to highincentive food pictures (Goldstone et al. 2009). Pronounced increases in activation of orbitofrontal and insular cortex, amygdala, and striatum were observed when contrasting high- and low incentive stimuli during deprived but not satiated state. Presenting symbolic visual representations of food items, in particular of high incentive value, is accordingly sufficient to elicit motivational responding in humans. Two further studies relied to an even greater extent on the presentation of symbolic stimuli and mental imagery. Specifically, a restaurant-like situation was realized, in which participants' brain activity was measured while they read and chose between menus items consisting of entrée, dinner, and dessert which were tailored individually to be of low and high incentive value (Hinton et al. 2004; Piech et al. 2009). A PET-study revealed that food deprivation was associated with increased BOLD activity in several structures of the motive circuitry (see Table 142.2). Furthermore, regions in the orbitofrontal cortex were particularly activated when reading high incentive menu items in a deprived state (Hinton et al. 2004). Using an event-related fMRI design, a follow-up study revealed two regions in orbitofrontal cortex, which were similarly showing an interaction of incentive value and motivational state. In addition, irrespective of food deprivation, amygdala activation was increased for menu items of high compared to low incentive value (Piech et al. 2009). Overall, food deprivation increases the incentive value of visual representations of food-related stimuli in the motive circuitry, possibly specifically for high-incentive stimuli.

Deprivation effects on the processing of taste stimuli were investigated in two studies. The study by Uher and colleagues (2006) included a taste condition in which processing of chicken broth and chocolate milk was compared to a control condition (artificial saliva). Deprivation did not alter the activity in structures of the motive circuitry when processing these complex gustatory stimuli. Studying pure taste stimuli, a recent study revealed deprivation effects in the motive circuitry (Haase et al. 2009; see Table 142.2), which, however, were most pronounced for the highly pleasant sucrose and mildly unpleasant citric acid stimuli. Overall, these studies reveal a pattern of findings similar to studies examining visual processing.

From a theoretical perspective, these studies revealed deprivation effects on food stimulus processing either in passive viewing or in active attention conditions, which were low in processing demand. Recent research suggests that task focus may have pronounced effects on food processing even when comparing passive viewing with evaluative rating tasks (Bender et al. 2009). It is therefore interesting to consider studies in which deprivation effects were investigated while participants performed explicit tasks. The first of these studies (Morris and Dolan 2001) used PET to explore whether food deprivation specifically enhances the recognition of food pictures. Blocks of either 
food or non-food pictures were presented and participants' task was to indicate whether the seen pictures was included in a memory set presented immediate before the scanning took part. Furthermore, participants were initially tested in a deprived state and fed to satiety in the course of the experiment. Hunger ratings were positively correlated with BOLD activity in the insular cortex, Nc. Accumbens, and hypothalamus, irrespective whether participants viewed food or object pictures. Specificity for food picture processing was seen in the right posterior orbitofrontal cortex, which showed a positive relationship to hunger ratings. Several regions in the brain showed a relationship to memory performance, category-independent (e.g., orbitofrontal cortex) and categorydependent (e.g., left amygdala, insula), which, however, was not modulated by the motivational state. A second study examined the effects of spatial attention and food deprivation (Mohanty et al. 2008). The attention task consisted of valid, invalid, and neutrally cued responses to laterally presented target stimuli (donuts or tools) and foils (danishes and screws). In a mixed event-related paradigm, food and nonfood pictures were shown in separate blocks. Deprivation increased BOLD activity in the amygdala to blocks containing food pictures in a deprived as compared to a satiated state (see Table 142.2 for other regions). This finding was specific to food picture processing and not observed in blocks presenting tool items. A further aim of this study was to examine the relationship of anticipatory activity in neural structures of the spatial attention network and speed of responding. Deprivation specifically modulated anticipatory activity in parietal and posterior cingulate cortex during blocks of food targets. Furthermore, medial sectors of the orbitofrontal cortex were related to the performance in the attention task when hungry and lateral orbitofrontal cortex during satiety. A third study examined deprivation effects on the processing of high and low caloric food and object pictures in the context of an explicit object-based attention task (Siep et al. 2009). In separate blocks, attentional focus was directed either toward food items, towards the color of the picture, or to bars positioned at lateral sites of the pictures. A strict analysis revealed no significant three-way interaction of picture type, attention focus and deprivation. Less stringent analysis revealed that regions in the insular cortex, medial and inferior orbitofrontal cortex, and striatum showed an interaction between picture type (low calorie, high calorie food, objects) and deprivation. In these structures, low compared to high calorie stimuli seemed to elicit increased activity in the satiated state, while high compared to low calorie stimuli elicit increased activity in the deprived state. Furthermore, these effects were independent from the attention task. With regard to the effects of paying attention to food, activity in amygdala and orbitofrontal cortex was increased when food pictures where task relevant, however, the effect was similarly pronounced for low- and high calorie stimuli. Overall, deprivation effects were investigated in active task contexts by several studies adapting established paradigms from cognitive neuroscience. Albeit preliminary, evidence for modulations of incentive value by food deprivation seems ambiguous. Embedding food items in the structure of cognitive tasks may diminish their salience. The use of a passive viewing condition is recommended in order to determine the activation of structures of the motive circuitry independent from explicit task demands. Furthermore, although food stimuli are task-relevant in these studies, there are striking differences to natural situations in which goal-relevance of food stimuli serves to support adaptive behaviors.

One reading of the information depicted in Table 142.2 is that core structures of the motive circuitry are sensitive to both incentive value of food stimuli and internal state. However, there is considerable variety in experimental findings across studies. No single structure received unanimous support and positive findings showed considerable variability with regard to hemispheric lateralization. Consideration of methodological variables might be particularly informative to identify issues, which need to be addressed in future research (see Table 142.1).

The number of participants pronouncedly varied across studies raising the concern that differences in findings may simply arise because of differences in statistical power. While hours of deprivation 
greatly varied across studies (6-24h), there seems no simple relationship to the observation of deprivation effects. However, considering also the great variance with regard to time of testing, circadian rhythm might moderate the effects of food deprivation on food-related stimulus processing. Overall, a paradigmatic approach seems valuable to empirically delineate appropriate sample sizes and hours of deprivation and to reveal circadian rhythm effects.

The majority of studies presented visual stimuli. Food pictures were presented in six studies with most recent studies varying caloric content of the stimulus materials. Written descriptions of menus (starter, entrée, dessert) were used in two studies, which individually varied preference for the menus. Obviously, the quality of stimulus materials is of great importance in revealing deprivation effects. The development of freely shared stimulus materials, calibrated according to major dimensions of eating and ingestion might facilitate progress in the field, similar to the development of the International Affective Picture Series (IAPS, Lang et al. 2008) in the domain of emotion research.

In summary, insights about the neural organization of the feeding system derived from animal research can serve as theoretical foundation to investigate the neural organization of the human feeding system in general, and regarding the effects of deprivation in particular. The rather small number of studies provides promising evidence for the hypothesis that core structures of the motive circuitry, associated with reward perception and adaptive behavior organization, are sensitive to variations in internal state. However, given the importance of deprivation, the widespread practice of voluntary restricting food intake by dieting and restrained eating, a much larger database is needed to realize the potential of the neuroscientific perspective on the understanding of both basic mechanism of food intake regulation and eating-related disorders.

\subsection{Overfeeding, Satiation and Incentive Value}

A complementary perspective on the effects of deprivation is provided by studies investigating sensory-specific satiety and overfeeding (see Tables 142.3 and 142.4). Several studies examined the phenomenon of sensory-specific satiety, which denotes that the incentive value and rated pleasantness decreases to food, which is eaten to satiety to a greater extent than for other foods. In an fMRIstudy (O'Doherty et al. 2000), processing of vanilla and banana odors was investigated in two sessions (pre- and post-meal), which were identical with the exception that the second session took part after eating bananas to satiety. The orbitofrontal cortex was related to olfactory sensory-specific satiety showing a specific decrease in BOLD signal to banana odors in the post- as compared to the pre-meal condition. These findings are consistent with single cell recording in the orbitofrontal cortex of macaques, which revealed that olfactory neurons decreased responding to food odors eaten to satiety (Critchley and Rolls 1996). A further PET- study investigated changes in brain activity related to eating chocolate. Specifically, brain activity was measured while participants were given a single piece of chocolate immediately before the scanning period, tracking the hedonic experience of chocolate from being highly pleasurable to being highly aversive (Small et al. 2001). Among other regions (see Table 142.4), medial orbitofrontal cortex, insular cortex, and striatal regions showed a decrease in activity with increasing satiety. Of particular interest, lateral orbitofrontal cortex showed opposite effects, i.e., enlarged activity when chocolate was perceived as highly aversive. Accordingly, adding further evidence for the role of orbitofrontal cortex and sensory-specific satiety, medial and lateral orbitofrontal cortex appear to be selectively responsive during states in which approach and avoidance dispositions were dominant. Effects of sensory-specific satiety were furthermore investigated in the context of associative conditioning paradigm, in which odors were paired with task-relevant visual stimuli (Gottfried et al. 2003). Devaluation affected several structures of the motive circuitry 
Table 142.3 Schematic overview of fMRI- and PET-studies investigating effects of satiation, and overfeeding

\begin{tabular}{|c|c|c|c|c|c|c|}
\hline Study & $\mathrm{N}$ & Effect & Manipulation check & Method & Task & Stimuli \\
\hline $\begin{array}{l}\text { O'Doherty, et al. } \\
(2000)\end{array}$ & 5 & $\begin{array}{l}\text { Sensory-specific } \\
\text { satiety }\end{array}$ & Self-report & $\begin{array}{l}3 \text { T fMRI } \\
\text { Block-Design }\end{array}$ & No task & Vanilla and banana odors \\
\hline Small et al. (2001) & 9 (5 women $)$ & $\begin{array}{l}\text { Sensory-specific } \\
\text { satiety }\end{array}$ & Self-report & PET Block-Design & Evaluative rating task & Pieces of chocolate \\
\hline $\begin{array}{l}\text { Gottfried } \\
\quad \text { et al. (2003) }\end{array}$ & 13 & $\begin{array}{l}\text { Sensory-specific } \\
\text { satiety }\end{array}$ & Self-report & $\begin{array}{l}\text { 1,5 T fMRI } \\
\text { Event-related } \\
\text { Design }\end{array}$ & $\begin{array}{l}\text { Reaction time task (CS) } \\
\text { and Implicit associative } \\
\text { conditioning }\end{array}$ & $\begin{array}{l}\text { CS: Visual images } \\
\text { US: Odors }\end{array}$ \\
\hline $\begin{array}{l}\text { Holsen } \\
\text { et al. (2005) }\end{array}$ & $\begin{array}{l}9 \text { children } \\
\text { (5 women) }\end{array}$ & Pre- vs. Post meal & & $\begin{array}{l}3 \mathrm{~T} \text { fMRI } \\
\text { Block-Design }\end{array}$ & Memory task & $\begin{array}{l}\text { Pictures of foods, } \\
\text { animals and objects }\end{array}$ \\
\hline $\begin{array}{l}\text { Cornier } \\
\quad \text { et al. (2007) }\end{array}$ & 25 (13 women) & $\begin{array}{l}2 \text { days of } \\
\quad \text { overfeeding }\end{array}$ & $\begin{array}{l}\text { Control of food } \\
\text { intake }\end{array}$ & $\begin{array}{l}3 \mathrm{~T} \text { fMRI } \\
\text { Block-Design }\end{array}$ & No task & $\begin{array}{l}\text { Pictures of high- and low } \\
\text { incentive foods and objects }\end{array}$ \\
\hline $\begin{array}{l}\text { Cornier } \\
\quad \text { et al. (2009) }\end{array}$ & $\begin{array}{l}22, \text { thin }(10 \text { women }) \\
19, \text { reduced obese } \\
\text { ( } 10 \text { women })\end{array}$ & $\begin{array}{l}2 \text { days of } \\
\text { overfeeding }\end{array}$ & $\begin{array}{l}\text { Control of food } \\
\text { intake }\end{array}$ & $\begin{array}{l}3 \mathrm{~T} \text { fMRI } \\
\quad \text { Block-Design }\end{array}$ & No task & $\begin{array}{l}\text { Pictures of high- and low } \\
\text { incentive foods and objects }\end{array}$ \\
\hline
\end{tabular}

Summary of selected methodological aspects of fMRI- and PET-studies examining satiation and overfeeding 
Table 142.4 Key findings of effects due to satiation and overfeeding

\begin{tabular}{|c|c|c|c|c|c|c|c|}
\hline$\underline{\text { Study }}$ & Effect & Orbitofrontal cortex & Insular Cortex & Amygdala & Striatum & Hypothalamus & Other regions \\
\hline $\begin{array}{l}\text { O'Doherty } \\
\text { et al. (2000) }\end{array}$ & Pre-> post-meal & $\mathrm{R}$ & & & 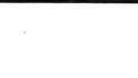 & & \\
\hline \multirow[t]{2}{*}{$\begin{array}{l}\text { Small } \\
\qquad \text { et al. (2001) }\end{array}$} & $\begin{array}{l}\text { rCBF decreases with } \\
\text { decreasing reward value }\end{array}$ & LR, medial & LR & & LR & & $\begin{array}{l}\text { ITG LR, MTG LR, OTG/Cereb LR, } \\
\text { Hipp L, Thal L }\end{array}$ \\
\hline & $\begin{array}{l}\text { rCBF increases with } \\
\text { decreasing reward value }\end{array}$ & $\mathrm{R}$, lateral & & & & & $\begin{array}{l}\text { Precen LR, IFG L, Cing, Parahipp R, } \\
\text { SMA R, MFG, middle FC L }\end{array}$ \\
\hline $\begin{array}{l}\text { Gottfried et al. } \\
\text { (2003) }\end{array}$ & Pre-> post-meal & $\begin{array}{l}\text { L, rostral } \\
\mathrm{R} \text {, caudal }\end{array}$ & $\mathrm{R}$, anterior & $\mathrm{L}$ & $\mathrm{L}$, ventral & & ACC R \\
\hline $\begin{array}{l}\text { Holsen } \\
\quad \text { et al. (2005) }\end{array}$ & $\begin{array}{l}\text { Motivational State } x \\
\text { Picture Type }\end{array}$ & $\begin{array}{l}\mathrm{R} \text {, medial } \\
\mathrm{LR} \text { lateral }\end{array}$ & $\mathrm{L}$ & $\mathrm{R}$ & $\mathrm{R}$ & & $\begin{array}{l}\text { MFG L, Oper LR, Parahipp R, Cing, } \\
\text { Fusiform L, IFG R, SFG LR, } \\
\text { ITG R, Postcen L, Precen LR, } \\
\text { Supra LR, Cereb/Fusiform R }\end{array}$ \\
\hline $\begin{array}{l}\text { Cornier } \\
\text { et al. (2007) }\end{array}$ & $\begin{array}{l}\text { EU>OF: (High Val> } \\
\text { Low Val) }\end{array}$ & & & & & $\mathrm{L}$ & IVC R \\
\hline \multirow[t]{2}{*}{$\begin{array}{l}\text { Cornier } \\
\quad \text { et al. (2009) }\end{array}$} & $\begin{array}{l}\text { Thin Subjects: EU>OF: } \\
\quad(\text { High Val > Obj) }\end{array}$ & & $\mathrm{x}$ & & & $\mathrm{X}$ & \\
\hline & $\begin{array}{l}\text { (Thin > Reduced Obese): } \\
\quad(\text { EU >OF): (High Val > Obj) }\end{array}$ & & LR & & & $\mathrm{R}$ & IVC R \\
\hline
\end{tabular}

This table summarizes effects of satiation and overfeeding on the activation of structures of the motive circuitry and other brain regions

$E U$ eucaloric state, $O F$ overfeeding, High Val high incentive food picture, Low Val low incentive food picture, Obj object picture, $L$ left, $R$ right, $A C C$ anterior cingulate cortex, Cereb cerebellum, Cing cingulate cortex, Fusiform fusiform gyrus. Hipp hippocampus, IFG inferior frontal gyrus, ITG inferior temporal gyrus, IVC inferior visual cortex, MFG medial frontal gyrus, middle FC middle frontal cortex, MTG medial temporal gyrus, OTG occipitotemporal gyrus, Oper basal operculum, Parahipp parahippocampal gyrus, $P C G$ posterior cingulate gyrus, Postcen postcentral gyrus, Precen precentral gyrus, SFG superior frontal gyrus, SMA supplementary motor area, Supra supramarginal gyrus, Thal thalamus, $r C B F$ regional cerebral blood flow 
(amygdala, ventral striatum, orbitofrontal cortex, insular cortex, see Table 142.4). Furthermore, regions in the amygdala and orbitofrontal cortex showed decreased BOLD signals specifically to the visual stimuli associated with the devalued odor while other brain regions (ventral striatum, insular cortex) showed both decreases and increases to visual stimuli paired with devalued and nondevalued odors, respectively. Investigating children, Holsen and colleagues (2005) presented food and object pictures in two sessions (pre- and post-meal) with participants eating a meal $(500 \mathrm{kcal})$ in between the sessions. Amygdala, orbitofrontal cortex, and insular cortex showed a selective decrease to food pictures when comparing pre- and post-meal sessions. Two further studies investigated the effects of overfeeding on the processing of food (low and high incentive) and control pictures (Cornier et al. 2007; Cornier et al. 2009). Towards this end, participants were tested even after 2 days of either eucaloric or overfed (30\% above eucaloric) energy intake. Overfeeding attenuated responding to high as compared to low incentive food pictures in the hypothalamus and inferior visual cortex (Cornier et al. 2007). These results were extended in a recent study investigating thin and obese participants, which reduced weight by $8 \%$ (Cornier et al. 2009). Regarding thin participants, food compared to object pictures elicited increased BOLD signals among other structures in orbitofrontal cortex, insular cortex, and ventral striatum in the eucaloric state. Overfeeding for 2 days resulted in reduced activity in these structures reaching significance in the insular cortex and hypothalamus. These effects of overfeeding were attenuated in obese participants. Overall, core structures of the reward matrix, in particular regions of the orbitofrontal cortex, showed a decrease in activity when fed to satiety.

\subsection{The Motivational Regulation of Attention}

The feeding system controls the organization of ingestive behaviors. Internal state and the perception of food-related cues from the immediate environment prime unique sets of perceptual-motor units that increase sensitivity to relevant stimuli at the appetitive and consummatory behavioral stage. According to this perspective, food deprivation effects operate at multiple levels, by increasing incentive value of food stimuli, and by regulating attention processes.

However, attention is not a unitary phenomenon but refers to a collection of disparate functional processes. For instance, recent research has begun to detail food deprivation effects on spatial attention mechanisms and object-based attention, which imply distinct neural mechanisms (Mohanty et al. 2008; Siep et al. 2009). Furthermore, attention is not only regulated according to explicit instructions by varying the task relevance of food stimuli, but is also passively captured by stimuli according to their motivational and emotional significance (Öhman 1986). When related to current motivational needs, stimuli may reflexively capture attentional resources to facilitate efficient responding.

Support for the obligatory nature of the motivational regulation of attention processes has been obtained in a study, in which food pictures were passively viewed, and participants performed an easy control task (detecting an occasional flicker of the images). Food deprivation enhanced the activity in higher order visual-associative regions (fusiform gyrus) when processing food pictures (LaBar et al. 2001). Conceptually similar results were observed when pictures were evaluated according to their likeability after viewing the pictures (Uher et al. 2006), but not when ratings of appealingness were made during picture viewing (Goldstone et al. 2009). Accordingly, although not explicitly designed to address the issue, there is some evidence that deprivation enhances attention processes to need-related food stimuli.

Two recent studies explicitly assessed the hypothesis that deprivation $(24 \mathrm{~h})$ sensitizes the processing of food cues (Stockburger et al. 2008, 2009a). Event-related brain potentials (ERPs) were measured 
in these studies, which provide a voltage measurement of neural activity that can be recorded noninvasively from multiple scalp regions. More specific, ERPs are considered to reflect summed postsynaptic potentials generated in the process of neural transmission and passively conducted through the brain and skull to the skin surface where they contribute to the electroencephalogram (EEG). Since ERPs are usually hidden in the larger background EEG activity, it is necessary to use multiple stimulus presentations and stimulus-locked signal averaging to extract the ERP signal from the background EEG activity. Biophysical considerations suggest that large-amplitude ERP components reflect widespread, synchronous sources in cortical regions. Brain activity locked to the processing of a stimulus becomes apparent as positive and negative deflections in the ERP waveform. The amplitude and latency of specific ERP components provide information regarding the strength and time course of underlying neural processes. Furthermore, given appropriate spatial sampling, the topography of ERP components can be used to estimate the neural generator sites by advanced analytic tools such as L2-Minimum-Norm-Estimate (L2-MNE; Junghöfer et al. 2006).

The first study was specifically designed to determine whether motivational state modulates early visual attention processes (Stockburger et al. 2008). A rapid serial presentation technique was used in which stimuli were presented for $330 \mathrm{~ms}$ without any perceivable interstimulus gap. Thus, this paradigm induces perceptually demanding conditions, which are deemed as necessary to reveal attention effects. Food stimuli were interspersed in a stream of pleasant, neutral, and unpleasant control stimuli drawn from various categories of human experience, which served as control stimuli to determine the specificity of deprivation effects on food picture processing. Results showed that deprivation specifically modulated the relatively early processing of food pictures. Between 170 and $320 \mathrm{~ms}$, the ERP waveform revealed enhanced posterior positive deflections for food pictures in hungry compared to satiated state (Fig. 142.3a). MNE source calculations revealed that these deprivation effects on food processing were associated with primary activations in posterior perceptual representation networks. In addition, secondary activations were suggested over anterior brain regions (Fig. 142.3b). However, spatial resolution was insufficient to determine whether this finding

\section{Deprivation Effects on Early Cortical Food Stimulus Processing}

a

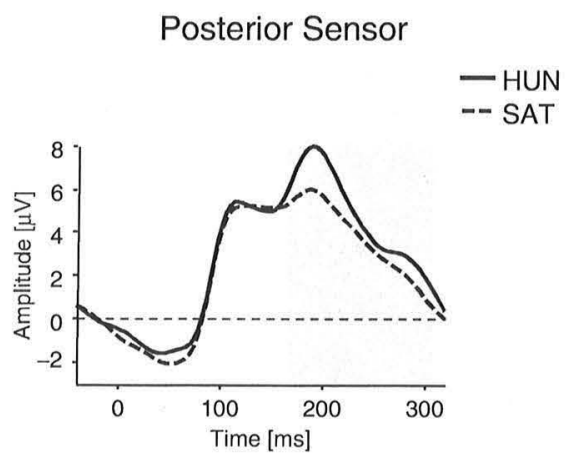

b

Difference Maps: Hungry - Satiated

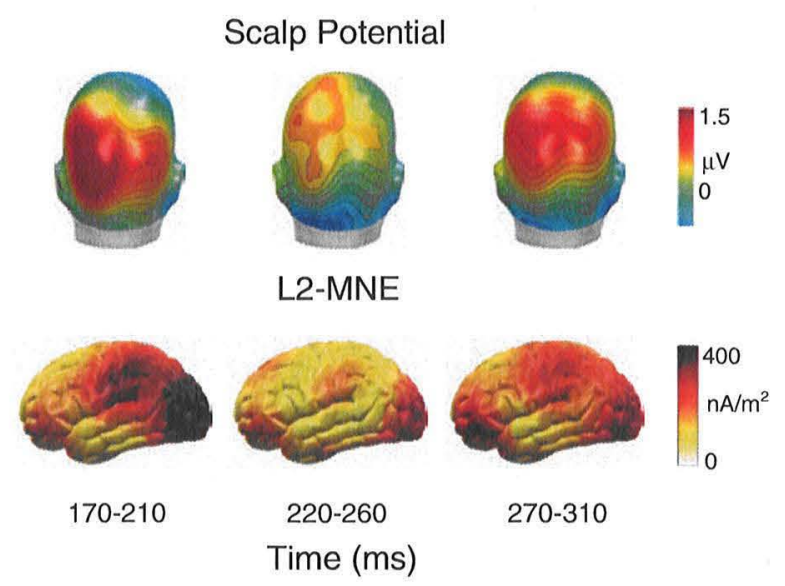

Fig. 142.3 (a) Representative ERP-waveforms for food pictures in the hungry (red lines) and satiated (black lines) states. (b) Scalp potential (back view) and L2-Minimum Norm estimates maps (right lateral view) show differences in processing food pictures in deprived and satiated state (Based on Stockburger et al. 2008) 
relates to orbitofrontal activations, which were observed when comparing food cue processing in hungry and satiated state and food stimuli varying in their incentive value (O'Doherty et al. 2000; Morris and Dolan 2001; Arana et al. 2003). These findings suggest that perceptual stimulus processing is gated in specific ways according to motivational state. According to a functional perspective, ERP modulations in this time window have been considered to reflect a call for processing resources in later capacity-limited processing stages implicated in conscious stimulus recognition (cf. Öhman 1986; Schupp et al. 2006).

These later processing stages related to working memory and stimulus recognition were the focus of another study in which food and flower pictures were presented as rapid serial stream for $660 \mathrm{~ms}$ (Fig. 142.4a and b; Stockburger et al. 2009a). A consistent body of evidence revealed that emotionally relevant pictures elicit increased late positive potentials (LPP) between 350 and $700 \mathrm{~ms}$ post-stimulus (Schupp et al. 2006). Similarly, food deprivation specifically enhanced the LPP component to food pictures (Fig. 142.4c). The assumption that increased positive potentials to food pictures in a hungry state reflects enhanced processing is supported by L2-MNE analyses, which revealed increased dipole strength over extended posterior visual processing regions (Fig. 142.4d). Thus, consistent with its presumed relation to conscious stimulus recognition, the LPP is linked to widespread activation broadcasting stimulus information to many associative cortical regions rather than reflecting local processing (Del Cul et al. 2007). Overall, in a state of food deprivation, food pictures seem to elicit a state of heightened selective attention in a capacity-limited processing stage, which is a critical gateway for the stimulus representation in working memory and conscious stimulus recognition. Furthermore, these findings were observed while participants passively viewed the stimulus materials and the food images were not task relevant. Consequently, the motivational regulation of visual processing appears to be a spontaneous and involuntary phenomenon, important characteristics of automatic processes.

Overall, electrophysiological measures of brain activity allow delineating the regulation of attention processes at the level of distinct processing stages. Internal motivational state sensitizes responding to need-related stimuli in processing stages mandatory for stimulus recognition. This mechanism seems highly adaptive from a functional perspective. The selective responding and evaluation of need-relevant stimuli is critical for the efficient organization of food-related behaviors.

\subsection{Food Deprivation and the Startle Reflex}

To obtain reliable measures of brain activity related to stimulus processing, neuroimaging methods require repeated stimulus presentations. Accordingly, in the case of food deprivation, stimuli are presented while participants are denied access to food. Unfortunately, the motivational orientation elicited in these protocols is potentially ambiguous. On the one hand, viewing food-related stimuli in deprived state may prompt associated appetitive responses. Alternatively, a state of frustrative non-reward may be induced, if participants are denied the immediate consumption of food.

Studies utilizing the startle probe methodology (see Table 142.5) may help to resolve this issue (Drobes et al. 2001; Mauler et al.2006). This research builds upon the notion that responding to emotionally and motivationally significant stimuli is organized by two basic brain circuits, one prompting appetitive responding and pleasant affects, and the other determining withdrawal and defense behaviors and unpleasant affect. The measurement of the defensive startle reflex allows inferring the engagement of basic motive systems, which is potentiated when elicited during an aversive state and inhibited during pleasant states. In their study, Drobes and colleagues (2001) presented a series of food pictures as well as emotional and neutral control pictures varying level 


\section{Deprivation Effects on Later Cortical Food Stimulus Processing}

a

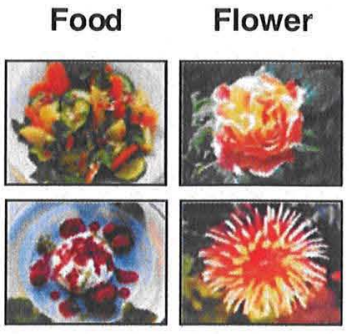

C

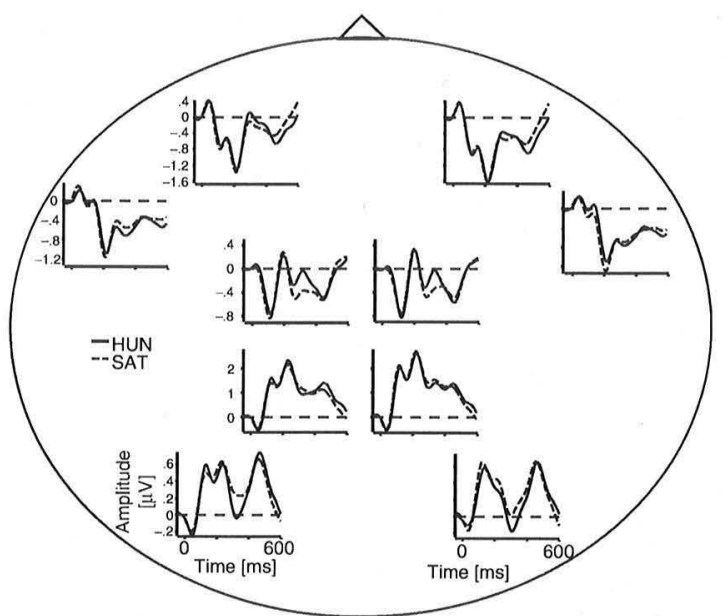

b

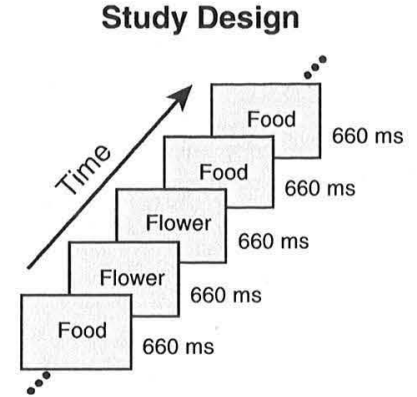

d
MNE (450-600 ms)

(450-600 ms)

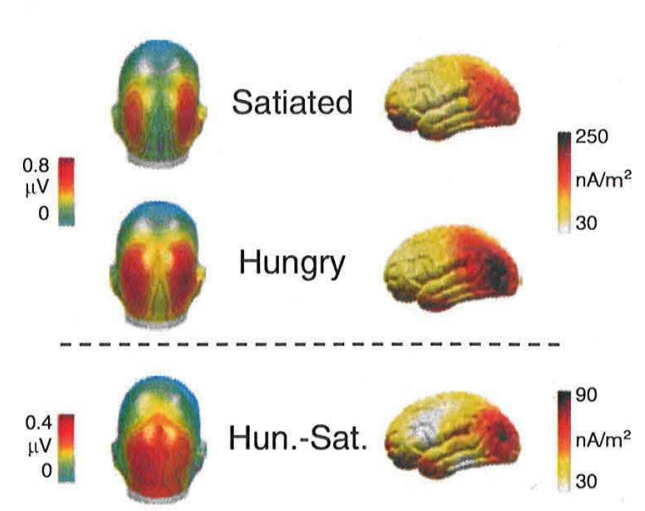

Fig.142.4 (a) Representative examples of the food and flower stimuli. (b) Illustration of the rapid serial visual presentation paradigm. Food and flower pictures were presented for $660 \mathrm{~ms}$ without perceivable interstimulus gap. (c) Representative ERP-waveforms for food pictures in the hungry (red lines) and satiated (black lines) states. (d) Scalp potential (back view) and L2-Minimum Norm estimates maps (right lateral view) show the topography of the LPP component for food and the difference between the hungry and satiated states (Based on Stockburger et al. 2009a)

Table 142.5 Key features of the startle reflex

1. The startle reflex is a defense response that prevents organ injury and interrupts ongoing mental and behavioral activity

2. The startle reflex is a whole body response that consists of rapid flexor movements cascading throughout the body

3. The reflex is elicited by sudden, unexpected, and intense stimuli. In the laboratory, acoustic stimuli (e.g., $50 \mathrm{~ms}$ duration, 90-110 dB loudness, and instantaneous rise time) are often used to elicit the reflex

4. Rapid eye closure is among the most reliable components of the startle response in humans and measured by recording the electrical activity of the orbicularis oculi muscle

5. The acoustic blink reflex shows an onset latency of $\sim 20-40 \mathrm{~ms}$ and usually peaks between 50 and $100 \mathrm{~ms}$

6. While the startle reflex is an obligatory response, its magnitude varies as a function of emotional, motivational, and attentional processes

This table lists the key features of the startle reflex 
of food deprivation across subjects $(0,6,24 \mathrm{~h})$. In a nondeprived state, food pictures revealed inhibited startle responses as compared to the other picture materials suggesting that these cues prompt an appetitive approach disposition. In contrast, startle reflexes elicited during food picture viewing were potentiated for both deprivation levels as compared to the nondeprived group. These findings were considered to reflect an aversive motivational reaction, which is attributed to a state of frustrative non reward, i.e., participants were not allowed immediate consumption (Drobes et al. 2001). However, another line of studies revealed that the active imagination of pleasant scenes triggered enhanced startle reflexes compared to neutral imagery contents (Miller et al. 2002). An alternative interpretation of the Drobes et al. (2001) and Mauler et al. (2006) findings is accordingly, that viewing food pictures elicited vivid imagination in the participants. Resolving the issue is of great theoretical importance and the startle probe methodology may serve as promising tool to disambiguate motivational orientation elicited by internal deprivation state and external food cue reactivity.

\subsection{Applications to Other Areas of Health and Disease}

Revealing the effects of food deprivation with regard to incentive value and attention processes provides highly relevant information for the obesity pandemic. The voluntary restriction of food intake for regulating body weight is an increasing phenomenon in many Western cultures. Such attempts in dieting and restrained eating are often accentuated towards foods considered as fattening (e.g., sweets, high-fat food). Specific food restrictions may be also due to moral and health concerns as is the case for instance in vegetarianism. It seems highly informative to determine the specificity of food restrictions on the processing of food stimuli with particular emphasis of affective attitudes and short- and long-term effects. For instance, a recent event-related brain potential study revealed the increased attention capture of meat pictures in vegetarians refraining from eating meat for several years (Stockburger et al. 2009b). Understanding food deprivation effects may be furthermore relevant in understanding eating disorders such as anorexia nervosa and bulimia.

\section{Summary Points}

- At the core of the feeding system are neural circuits that were laid down early during evolutionary history, in primitive cortex, sub-cortex, and midbrain.

- These motivational circuits are engaged by unconditioned food-related stimuli, determine general mobilization and approach behaviors of the organism, and mediate the shaping of the feeding system by learning and experience.

- Internal state variables exert a profound effect on the feeding system and neuroimaging methods appear promising to provide novel insights into the operation of food deprivation.

- Hemodynamic studies were reviewed providing some support for the notion that food deprivation increases the incentive value of food-related stimuli in core structures of the motive circuitry. There is evidence that these effects appear most robust for high-incentive stimuli.

- Furthermore, attention to need-related stimuli is regulated by motivational state. Event-related potential studies delineate motivated attention processes with high temporal resolution suggesting that deprivation effects facilitate perceptual processing in stages related to stimulus recognition and working memory representation. 
- Guided by animal research about the neural organization of the feeding system, electrophysiological, hemodynamic, and reflex measures of brain activity provide a window to probe deprivation effects on food stimulus processing.

- Given the sparse number of relevant studies, a considerable research effort is needed to reveal consistent and reliable findings related to deprivation.

- Understanding these effects seems important when considering that attempts to regulate body weight and eating-related disorders often include the voluntary restriction of food intake.

\section{Key Terms}

Ingestive behavior: Ingestive behaviors are comprised by appetitive and consummatory phases which depend on the integration of information about internal state, cues from the environment, behavioral state, and cognition.

Incentive motivation: Incentives arouse motivated behaviors and form the target for goal-direct behaviors. Incentive motivation is determined by external stimuli and internal states.

Motive circuitry: Cortical, subcortical, and brainstem neural structures implicated in reward perception and activation of adaptive behaviors.

Functional magnetic resonance imaging: Neural activity is coupled with blood oxygenation level dependent (BOLD) signal changes that can be measured with MRI. Assessment of shortterm changes can be used to infer functional neural activity associated with food stimulus processing in core structures of the motive circuitry.

Motivated attention: In natural environments, attention is dictated by motivational significance of salient stimuli and internal states.

Event-related brain potentials: Electrophysiological recordings of brain activity associated with food stimulus processing. Providing a high temporal resolution, event-related potential recordings allow measuring the motivational regulation of attention by food deprivation.

Acknowledgments We thank Tobias Flaisch and Christoph Becker for their feedback on an earlier version of this manuscript. This work was supported by the German Research Foundation (grant Schu 1074/11-2, Schu 1074/10-3), by the European Community FP7 (grant 'TEMPEST', 223488), and the German Federal Ministry of Education and Research (grant 'EATMOTIVE', 0315671).

\section{References}

Arana FS, Parkinson JA, Hinton E, Holland AJ, Owen AM, Roberts AC. J Neurosci. 2003;23:9632-8.

Barbano MF, Cador M. Behav Neurosci. 2005;119:1244-53.

Beaver JD, Lawrence AD, van Ditzhuijzen J, Davis MH, Woods A, Calder AJ. J Neurosci. 2006;26:5160-6.

Bender G, Veldhuizen MG, Meltzer JA, Gitelman DR, Small DM. Eur J Neurosci. 2009;30:327-38.

Berridge KC, Kringelbach, ML. Psychopharmacology 2008;199:457-80.

Berthoud HR, Morrison C. Annu Rev Psychol. 2008;59:55-92.

Cornier MA, Von Kaenel SS, Bessesen DH, Tregellas JR. Am J Clin Nutr. 2007;86:965-71.

Cornier MA, Salzberg AK, Endly DC, Bessesen DH, Rojas DC, Tregellas JR. PLoS One. 2009;4:e6310.

Critchley HD, Rolls ET. J Neurophysiol. 1996;75:1673-86.

Del Cul A, Baillet S, Dehaene S. PLoS Biol. 2007;5:2408-23.

Delparigi A, Gautier JF, Chen K, Salbe AD, Ravussin E, Reiman E, Tataranni, PA. Ann N Y Acad Sci. 2002;967:389-97.

Delparigi A, Chen K, Salbe AD, Reiman EM, Tataranni PA. NeuroImage. 2005;24:436-43.

Drobes DJ, Miller EJ, Hillman CH, Bradley MM, Cuthbert BN, Lang PJ. Biol Psychol. 2001;57:153-77. 
Goldstone AP, de Hernandez CG, Beaver JD, Muhammed K, Croese C, Bell G, Durighel G, Hughes E, Waldman AD, Frost G, Bell JD. Eur J Neurosci. 2009;30:1625-35.

Gottfried JA, O’Doherty J, Dolan RJ. Science 2003;301:1104-7.

Haase L, Cerf-Ducastel B, Murphy C. NeuroImage 2009;44:1008-21.

Hinton EC, Parkinson JA, Holland AJ, Arana FS, Roberts AC, Owen AM. Eur J Neurosci. 2004;20:1411-8.

Holland PC, Gallagher M. Curr Opin Neurobiol. 2004;14:148-55.

Holsen LM, Zarcone JR, Thompson TI, Brooks WM, Anderson MF, Ahluwalia JS, Nollen NL, Savage CR. NeuroImage 2005;27:669-76.

Junghöfer M, Peyk P, Flaisch T, Schupp HT. Prog Brain Res. 2006;156:123-43.

Kalivas PW, Nakamura M. Curr Opin Neurobiol. 1999;9:223-7.

Keys A, Brozek J, Henschel A, Mickelson O, Taylor HL. The biology of human starvation. 2 vols. Minneapolis: University of Minnesota Press; 1950.

Killgore WD, Young AD, Femia LA, Bogorodzki P, Rogowska J, Yurgelun-Todd DA. NeuroImage 2003;19:1381-94.

Kringelbach ML, O’Doherty J, Rolls ET, Andrews C. Cereb Cortex. 2003;13:1064-71.

Lang PJ, Bradley, MM, Cuthbert BN (2008). International affective picture system (IAPS): Affective ratings of pictures and instruction manual. Technical Report A-8. University of Florida, Gainesville, FL.

LaBar KS, Gitelman DR, Parrish TB, Kim YH, Nobre AC, Mesulam MM. Behav Neurosci. 2001;115:493-500.

Logothetis NK. Nature 2008;12:869-78.

Mauler BI, Hamm AO, Weike AI, Tuschen-Caffier B. J Abnorm Psychol. 2006;115:567-79.

Miller MW, Patrick CJ, Levenston GK. Psychophysiology 2002;39:519-29.

Mohanty A, Gitelman DR, Small DM, Mesulam MM. Cereb Cortex. 2008;18:2604-13.

Morris JS, Dolan RJ. J Neurosci. 2001;21:5304-10.

O’Doherty J, Rolls ET, Francis S, Bowtell R, McGlone F, Kobal G, Renner B, Ahne G. Neuroreport 2000;11:893-7.

Öhman A. Psychophysiology 1986;23:123-45.

Pavlov IP. Zwanzigjährige Erfahrungen mit dem objektiven Studium der höheren Nerventätigkeit (des Verhaltens) der Tiere. Berlin: Akademischer; 1953.

Petrovich GD, Holland PC, Gallagher M. J Neurosci. 2005;25:8295-302.

Petrovich GD, Ross CA, Mody P, Holland PC, Gallagher M. J Neurosci. 2009;29:15205-12.

Pickens CL, Saddoris MP, Setlow B, Gallagher M, Holland PC, Schoenbaum G. J Neurosci. 2003;23:11078-84.

Piech RM, Lewis J, Parkinson CH, Owen AM, Roberts AC, Downing PE, Parkinson JA. PLoS One. 2009;4:e6581.

Polivy J. J Am Diet Assoc. 1996;96:589-92.

Porubská K, Veit R, Preissl H, Fritsche A, Birbaumer N. NeuroImage 2006;32:1273-80.

Raynor HA, Epstein LH. Appetite 2003;40:15-24.

Schienle A, Schäfer A, Hermann A, Vaitl D. Biol Psychiatry. 2009;65:654-61.

Schupp HT, Flaisch T, Stockburger J, Junghofer M. Prog Brain Res. 2006;156:31-51.

Schupp HT, Stockburger J, Codispoti M, Junghöfer M, Weike AI, Hamm AO. J Neurosci. 2007;27:1082-9.

Siep N, Roefs A, Roebroeck A, Havermans R, Bonte ML, Jansen A. Behav Brain Res. 2009;198:149-58.

Small DM, Zatorre RJ, Dagher A, Evans AC, Jones-Gotman M. Brain 2001;124:1720-33.

Smith KS, Tindell AJ, Aldridge JW, Berridge KC. Behav Brain Res. 2009;196:155-67.

Spiegel TA, Shrager EE, Stellar E. Appetite 1989;13:45-69.

Stockburger J, Weike AI, Hamm AO, Schupp HT. Behav Neurosci. 2008;122:936-42.

Stockburger J, Schmalzle R, Flaisch T, Bublatzky F, Schupp HT. NeuroImage 2009a;47:1819-29.

Stockburger J, Renner B, Weike A, Hamm AO, Schupp HT. Appetite 2009b;52:513-6.

Swanson LW. Brain Res. 2000;886:113-64.

Tataranni PA, Gautier JF, Chen K, Uecker A, Bandy D, Salbe AD, Pratley RE, Lawson M, Reiman EM, Ravussin E. Proc Natl Acad Sci USA. 1999;96:4569-74.

Timberlake W. In: Mowrer RR, Klein SB, editors. Handbook of contemporary learning theories. Mahwah: Erlbaum; 2001. p. 155-209.

Timberlake W, Allison J. Psychol Rev. 1974;81:146-64.

Toates FM. Appetite 1981;2:35-50.

Uher R, Treasure J, Heining M, Brammer MJ, Campbell IC. Behav Brain Res. 2006;169:111-9.

Watts AG, Swanson LW. In: Gallistel CR, Pashler H, editors. Stevens' handbook of experimental psychology, volume 3 , learning, motivation, and emotion. New York: Wiley; 2002. p. 563-631.

Woods SC, Schwartz MW, Baskin DG, Seeley RJ. Annu Rev Psychol. 2000;51:255-77. 